thebmi

\title{
Editorials
}

\section{Reducing harm from alcohol}

BMJ 2009; 338 doi: http://dx.doi.org/10.1136/bmj.b1191 (Published 20 March 2009) Cite this as: BMJ 2009;338:b1191

\author{
Martin McKee, professor of European public health1, Paul Belcher, EU government affairs \\ advisor2, Tamara Hervey, professor of law3 \\ ${ }^{1}$ London School of Hygiene and Tropical Medicine, London WC1E 7HT \\ ${ }^{2}$ Royal College of Physicians, London NW1 4LE \\ ${ }^{3}$ University Of Sheffield, Sheffield S3 7ND
}

martin.mckee@lshtm.ac.uk

The UK must tackle the problem of cheap alcohol

The United Kingdom has a drink problem. Whether measured as alcohol related deaths, hospital admissions, or crimes, its condition has been deteriorating markedly. And the problem is not confined to a small number of people going on a binge each weekend. Mortality from cirrhosis, a marker of more insidious harm, is now one of the highest rates in Europe, at a time when it is falling in many other European countries. 1

The reasons seem obvious. At a population level, consumption is driven by price, availability, and marketing.2 British supermarkets now sell beer more cheaply than bottled water. High street convenience shops, often only a short stagger apart, have entire walls lined with cheap alcohol. And alcohol producers - taking advantage of the latest advances in neurosciences that can, quite literally, read the minds of people they view as potential customers-have developed extremely sophisticated marketing techniques. 3 Britain is awash with low price, heavily marketed alcohol.

This is not, of course, the picture that the alcohol industry seeks to project. Learning from the tobacco industry, it has engaged in an extensive (and expensive) campaign that uses all the recognised characteristics of denialism, such as selectivity in citing studies, creation of impossible expectations of research, and logical fallacies. 4 Its aim has been to convince policy makers that the problem (if one even exists) is confined to a small number of heavy drinkers. We are assured that British drinking patterns reflect our culture and climate and have nothing to do with clever marketing of cheap alcohol. The industry's preferred solution involves largely ineffective educational initiatives, 5 complemented by actions that are effective but simply reduce the worst effects of acute intoxication. What it does not want is anything that will reduce the overall level of consumption, and by extension, its profits.

Successive UK governments have shown some signs of understanding the true nature of the problem, even if they were reluctant to tackle it adequately. Taxes on alcohol have been increased as an explicit public health strategy and, largely through voluntary agreements, there have been some constraints on 
advertising. However, recent proposals by the Scottish government and the chief medical officer for England to impose a minimum price on alcohol move on to new ground. 6

Unlike the industry, those advocating minimum prices are acting on a systematic, rather than selective, review of the evidence. The authors of that review, funded by the English Department of Health, drew on numerous existing systematic reviews of the roles of price and promotions on consumption, and of consumption on health and social harm.7 As with any complex social phenomenon, less evidence was available in some areas than would be ideal, and a few studies were inconsistent, but the overall picture was clear. It confirmed beyond reasonable doubt that low prices and the increasingly diverse forms of marketing fuel consumption and thus alcohol related harm.

The measures being proposed are extremely modest but offer considerable rewards. The imposition of a minimum price of $£ 0.40$ ( $€ 0.43 ; \$ 0.56$ ) per unit of alcohol would cost a moderate drinker only $£ 0.11$ more a week and would have a very small effect on his or her consumption. The effect would be much greater for underage and heavy drinkers, and-when applied to data from England-would lead to a predicted saving in healthcare costs of $£ 25 \mathrm{~m}$ a year, with a further saving of $£ 17 \mathrm{~m}$ to the criminal justice system.7

The industry's response is predictable, not least because it employs some of the same public relations companies that sought to undermine the evidence on passive smoking and health.8 Amusing but improbable stories will be placed in the media describing supposed unintended consequences of increased prices. The scale of the price rises will be exaggerated (a medium glass of wine for $£ 0.80$ does not seem so expensive). The image so carefully cultivated of the problem being limited to a few binge drinkers will be used to portray price rises as an attack on ordinary people.

The industry may also invoke European law by suggesting that a minimum price would be contrary to the rules of the single market. If it was selling tobacco, it might have an argument (with a case currently before the European Court of Justice), because the relevant European directive does allow manufacturers to set a maximum price, which could be lower than a government imposed minimum.9 However, the corresponding directive on alcohol makes no such provision.10 Under the general treaty provisions, however, a foreign producer could possibly argue that its inability to discount would make it difficult to break into the UK market. The government would be able to invoke a strong public health defence, a principle established in European Union law, by showing that its measures were proportionate and the only way to protect the public interest. That would be possible given the scale of the problem and the evidence that a comprehensive multi-faceted policy that deals with price, availability, and marketing is most effective.

Observers may have a sense of déjà vu. The Scottish government and the English chief medical officer advocated a ban on smoking in public places when this was opposed by English ministers, and in the face of an intensive campaign of misrepresentation by the tobacco industry. Tackling powerful vested interests for the sake of public health is never easy, but sometimes it has to be done.11

\section{Niche marketing of alcopops 12}

The alcohol industry's approach to marketing is exemplified by a comparison of two alcopops, Mad Dog (a fortified fruit wine), and Bacardi Breezer (premixed spirits and fruit flavours). 
Mad Dog is aimed at young drinkers with little disposable income. The taste of alcohol is disguised by sweet and fruity flavours. A screw top makes it easier to carry when drinking illicitly outdoors. A high alcohol content satisfies the need for rapid intoxication. It is sold mainly from small grocery stores where it is hard to enforce age limits. There was no high profile mass media marketing, firstly because it would probably not have been cost effective, but also because it might have attracted the attention of policy makers.

Bacardi Breezer is aimed at older adolescents, especially those aspiring to success. It gains credibility from the international branding of Bacardi rum. It is marketed through heavyweight aspirational advertising and sponsorship deals. It is designed to be drunk from the bottle, to give the consumer the opportunity to identify with the brand and use the product's brand value to communicate with their peers. It is sold in licensed premises as well as off licences, and its high price communicates quality and sophistication.

\section{Notes}

Cite this as: BMJ 2009;338:b1191

\section{Footnotes}

- Competing interests: None declared.

- Provenance and peer review: Commissioned; not externally peer reviewed.

\section{References}

1. Leon DA, McCambridge J. Liver cirrhosis mortality rates in Britain from 1950 to 2002: an analysis of routine data. Lancet2006;367:52-6.

2. Room R, Babor T, Rehm J. Alcohol and public health. Lancet2005;365:519-30.

3. Astolfi L, De Vico Fallani F, Cincotti F, Mattia D, Bianchi L, Marciani MG, et al. Neural basis for brain responses to TV commercials: a high-resolution EEG study. IEEE Trans Neural Syst Rehabil Eng2008;16:52231.

4. Diethelm P, McKee M. Denialism: what is it and how should scientists respond? Eur J Publ Health2009;19:2-4.

5. Babor T, Caetano R, Casswell S, Edwards G, Giesbrecht N, Graham K, et al. Alcohol: no ordinary commodity —research and public policy. Oxford: Oxford University Press, 2003.

6. Scottish Government. Changing Scotland's relationship with alcohol: a framework for action. 2009. www.scotland.gov.uk/Publications/2009/03/04144703/0.

7. Booth A, Brennan A, Meier PS, O'Reilly DT, Purshouse R, Stockwell T, et al. The independent review of the effects of alcohol pricing and promotion. Sheffield: School of Health and Related Research, 2008.

8. McKee M. A European alcohol strategy: Will the opportunity be missed? BMJ2006;333:871-2.

9. Council of the European Communities. Council Directive 95/59/EC of 27 November 1995 on taxes other than turnover taxes which affect the consumption of manufactured tobacco. Official J Eur Communities 1995;L291(6 Dec): $40-5$.

10. Council of the European Communities. Council Directive 92/83/EEC of 19 October 1992 on the harmonization of the structures of excise duties on alcohol and alcoholic beverages. Official J Eur Communities1992;L316(31 Oct):29-31. 
11. Ibsen H. An enemy of the people. London: Faber, 1997.

12. Jackson MC, Hastings G, Wheeler C, Eadie D, Mackintosh AM. Marketing alcohol to young people: implications for industry regulation and research policy. Addiction 2000;95(suppl 4):S597-608. 